\title{
Gene expression profiling demonstrates that TGF- $\beta 1$ signals exclusively through receptor complexes involving Alk5 and identifies targets of TGF- $\beta$ signaling
}

\author{
Göran Karlsson, ${ }^{1,2}$ Yingchun Liu, ${ }^{2,3}$ Jonas Larsson,, ${ }^{1,2}$ Marie-José Goumans, ${ }^{4}$ \\ Ju-Seog Lee, ${ }^{5}$ Snorri S. Thorgeirsson, ${ }^{5}$ Markus Ringnér, ${ }^{2,3}$ and Stefan Karlsson ${ }^{1,2}$ \\ ${ }^{1}$ Department of Molecular Medicine and Gene Therapy, Institute of Laboratory Medicine, and ${ }^{2}$ The Lund Strategic \\ Research Center for Stem Cell Biology and Cell Therapy, Lund University Hospital, Lund, Sweden; ${ }^{3}$ Complex Systems Division, \\ Department of Theoretical Physics, Lund University, Lund, Sweden; ${ }^{4}$ Department of Cardiology, Heart Lung Center, \\ Utrecht, the Netherlands; and ${ }^{5}$ Laboratory of Experimental Carcinogenesis, National Cancer Institute, Bethesda, Maryland \\ Submitted 20 December 2004; accepted in final form 9 March 2005
}

\begin{abstract}
Karlsson, Göran, Yingchun Liu, Jonas Larsson, Marie-José Goumans, Ju-Seog Lee, Snorri S. Thorgeirsson, Markus Ringnér, and Stefan Karlsson. Gene expression profiling demonstrates that TGF- $\beta 1$ signals exclusively through receptor complexes involving Alk5 and identifies targets of TGF- $\beta$ signaling. Physiol Genomics 21: 396-403, 2005. First published March 15, 2005; doi:10.1152/ physiolgenomics.00303.2004.- - Transforming growth factor- $\beta 1$ (TGF- $\beta$ ) regulates cellular functions like proliferation, differentiation, and apoptosis. On the cell surface, TGF- $\beta$ binds to receptor complexes consisting of TGF- $\beta$ receptor type II (T $\beta$ RII) and activin-like kinase receptor-5 (Alk5), and the downstream signaling is transduced by Smad and MAPK proteins. Recent data have shown that alternative receptor combinations aside from the classical pairing of T $\beta$ RII/Alk5 can be relevant for TGF- $\beta$ signaling. We have screened for alternative receptors for TGF- $\beta$ and also for gene targets of TGF- $\beta$ signaling, by performing functional assays and microarray analysis in murine embryonic fibroblast (MEF) cell lines lacking Alk5. Data from TGF- $\beta$ stimulated $A l k 5^{-1-}$ cells show them to be completely unaffected by TGF- $\beta$. Additionally, 465 downstream targets of Alk5 signaling were identified when comparing Alk5 $5^{-/-}$or TGF- $\beta$-stimulated Alk5 $5^{+/+}$ MEFs with unstimulated $A l k 5^{+/+}$cells. Our results demonstrate that, in MEFs, TGF- $\beta$ signals exclusively through complexes involving Alk5, and give insight to its downstream effector genes.
\end{abstract}

signal transduction; Smad; microarrays

TRANSFORMING GROWTH FACTOR- $\beta 1$ (TGF- $\beta$ ) is ubiquitously expressed during embryonic development and in most adult tissues, regulating proliferation, differentiation, and apoptosis (18). Although much is known about the mechanisms of TGF- $\beta$ signaling, many target genes remain elusive, and the responses to TGF- $\beta$ are highly context dependent, varying with cell type and physiological state (15). In recent years, a large number of studies have attempted to elucidate the mechanisms of TGF- $\beta$ function via knockout mouse models either for TGF- $\beta$ receptors, the ligands, or downstream signaling proteins. As expected, these mice have various abnormalities in development, regulation of immune response, vessel formation, wound healing, and hematopoiesis (2).

Because of its importance in several different contexts, thorough investigations have led to considerable knowledge about the mechanisms of TGF- $\beta$ signal transduction (13). TGF- $\beta$ belongs to a superfamily of cytokines that also includes

Article published online before print. See web site for date of publication (http://physiolgenomics.physiology.org).

Address for reprint requests and other correspondence: M. Ringnér, Complex Systems Division, Dept. of Theoretical Physics, Lund Univ., Sölvegatan 14A, 22362 Lund, Sweden (e-mail: markus@thep.lu.se). activins/inhibins, bone morphogenetic proteins (BMPs), growth differentiation factors, and a few other related proteins. The TGF- $\beta$ family receptors consist of type I and type II transmembrane serine/threonine kinase receptors. On the cell surface, TGF- $\beta$ binds to the constitutively active T $\beta$ RII. Upon binding of the ligand, two T $\beta$ RIIs and two TGF- $\beta$ type I receptors $(\mathrm{Alk} 5 \mathrm{~s})$ are brought together, forming a heterotetrameric complex. The kinase domain of Alk5 is phosphorylated by T $\beta$ RII, and subsequently Alk5 phosphorylates and activates the intracellular receptor-activated (R)-Smads (Smad2 and -3), which heteroligomerize with the co-mediator, Smad4. This complex translocates into the nucleus, where it recruits transcriptional co-activators and co-repressors to control gene expression. In addition, it has been reported that phosphorylation of Alk5 initiates other pathways of signaling, including the mitogen-activated protein kinase (MAPK) family pathways, comprised of the extracellular signal-regulated kinase (ERK) pathway, c-Jun $\mathrm{NH}_{2}$-terminal kinase (JNK) pathway, and the p38 pathway. The only known function of T $\beta R I I$ is the activation of Alk5, and signaling from solitary T $\beta$ RIIs has not been reported.

It was earlier thought that Alk5 was the only type I receptor conducting TGF- $\beta$ signaling. However, there is evidence that TGF- $\beta$ can bind to Alk1 in endothelial cells and that the subsequent signal transduction through Smad1/5/8 inhibits Alk5 signaling $(5,16)$. Additionally, in epithelial cells Alk2 is involved in TGF- $\beta$-induced epithelial-to-mesenchymal transdifferentiation (9). In this study, we have investigated the possibility of alternative receptors for TGF- $\beta$ signaling in fibroblasts, by stimulating Alk5-deficient murine embryonic fibroblasts (MEFs) with TGF- $\beta$. We conclusively demonstrate that Alk5 is necessary for TGF- $\beta$ signal transduction in these cells.

Additionally, we present transcriptional profiles of MEF cell lines that are either deficient in Alk5 signaling, have normal signaling, or are stimulated with TGF- $\beta$ and identify genes that are differentially expressed as a response to TGF- $\beta$ signaling. Our results create a data set of 465 targets of TGF- $\beta$ /Alk5 signaling, in which earlier unknown categories of gene targets are revealed.

\section{METHODS}

Generation and culture of MEF cell lines. Cre-loxP gene targeting of the Alk5 exon 3 and isolation of murine embryonic fibroblasts were performed as described (10). Cells were cultured in Dulbecco's modified Eagles medium (DMEM; GIBCO, Stockholm, Sweden) supplemented with $10 \%$ fetal bovine serum (FBS; GIBCO) and $1 \%$ 
penicillin-streptomycin (GIBCO). Four different cell lines were generated, two that were $A l k 5^{-1-}[\mathrm{knockout}(\mathrm{KO}) 1$ and $\mathrm{KO} 2]$ and two that were $A l k 5^{+/+}$[wild type (WT) 1 and WT2]. In the case of TGF- $\beta$ stimulation experiments, huTGF- $\beta 1$ (R\&D systems, Abingdon, UK) was added in a concentration of $10 \mathrm{ng} / \mathrm{ml}$ at $1,5,8$, or $16 \mathrm{~h}$ before cell confluency. Cells were trypsinized and harvested when confluent.

In the cell expansion experiment, $2 \times 10^{5}$ cells from the different cell lines were plated in $60-\mathrm{mm}$ plates and cultured with or without the presence of TGF- $\beta 1(10 \mathrm{ng} / \mathrm{ml})$. Cells were counted and medium was changed at 24,48 , and $72 \mathrm{~h}$ postseeding. Three independent experiments were performed.

Western blot analysis. Western blot analysis was performed as described (10).

Transcriptional reporter assays. Assays were performed as described (10).

RNA isolation and microarray hybridization. RNA from harvested MEFs, stored as a dry pellet at $-80^{\circ} \mathrm{C}$, was isolated using TRIzol reagent (Invitrogen, Stockholm, Sweden) according to manufacturer's protocol, and reverse transcription and hybridization to microarray slides were performed as described (14). Microarray glass slides containing $>37,000$ mouse cDNA clones (mouse, 36K; National Institute of Mental Health, Bethesda, MD) were used. Slides were scanned using an Axon 4000 scanner (Axon Instruments, Leusden, the Netherlands) and analyzed with GenePix pro v.4.0 software (Axon Instruments).

Ten microarrays were performed to identify downstream targets of TGF- $\beta$ signaling. These were made using one RNA extraction from the KO1 MEF line and two extractions from the KO2 line (KO2 and $\mathrm{KO} 2 \_2$ ), with one of the Alk5 $5^{+/+}$cell lines (WT1) as reference, or the two $A l k 5^{+/+}$cell lines (WT1 and WT2) stimulated with TGF- $\beta$ for 1 , 5 , and $16 \mathrm{~h}$ preharvest, again with the WT1 cell line as reference. Alk5 $5^{-1-}$ and TGF- $\beta$-stimulated samples were labeled with Cy5 and reference sample with $\mathrm{Cy} 3$ dye in all experiments, except for one dye-swap experiment (KO1_DS) performed to exclude technical errors. The KO2_2 extraction functioned as a technical repeat and was performed 6 mo after the KO2 experiment. The subsequent microarray analysis was carried out using a completely new batch of reagents.

In addition, three arrays were performed to investigate the possibility of alternative receptors for TGF- $\beta$ signaling. They include experiments done using cDNA from the two $A l k 5^{-1-}$ cell lines stimulated with TGF- $\beta$ for $8 \mathrm{~h}$, with cDNA from unstimulated cells of the same Alk5 $5^{-1-}$ cell line as reference, and one experiment using cDNA from RNA extractions of two independently harvested WT1 cultures.

Microarray data, including information about the mouse cDNA clones, are available at the National Center for Biotechnology Information (NCBI) Gene Expression Omnibus (GEO) website (http:// www.ncbi.nlm.nih.gov/geo/) with GEO accession no. GSE1742.

Analyses of microarray data. The data extracted with the use of GenePix were stored in BioArray Software Environment (BASE; Ref. 19), and BASE was used for quality control and normalization. Briefly, on the basis of the parameters extracted by the GenePix software, our quality filter required each spot to have a median-based signal-to-noise ratio of at least 3 for each channel and at least 50 foreground pixels. Spots that did not fulfill these requirements were treated as missing values in the subsequent analysis. In addition, for the 10 arrays used to identify targets of TGF- $\beta$ signaling, spots with more than two missing values across arrays were excluded from further analysis. Each experiment was subsequently normalized using LOWESS regression as implemented in BASE.

Next, we looked for clones showing a large variation in expression across arrays, and selected spots for which the standard deviation of $\log$ (base 2 ) expression ratios was $>0.5$. To identify clones differentially expressed between TGF- $\beta$-stimulated $A l k 5^{+1+}$ and $A l k 5^{-1-}$ cells, we employed the rank-based Wilcoxon test as implemented in the MCD software (12). To investigate whether differentially expressed clones were significantly associated with specific Gene On- tology (GO) terms (6), we used the GoMiner software (24). GoMiner accepts gene symbols as input, and we used ACID (17) to map our clones to gene symbols (based on UniGene mouse build 141). In the GoMiner analysis, differentially expressed clones were compared with all clones that passed the quality filter. GO terms with $P$-under $\leq$ 0.05 and at least five downregulated clones or $P$-over $\leq 0.05$ and at least five upregulated clones were selected for discussion. To investigate genes in common between our data and previous studies, public data sets were mapped to gene symbols according to UniGene mouse build 141, using ACID.

Quantitative RT-PCR. Quantitative (q)RT-PCR (TaqMan; Applied Biosystems, Stockholm, Sweden) was performed in an ABI Prism 7700 (Applied Biosystems), according to the manufacturer's protocol,

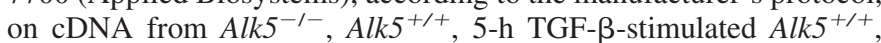
and TGF- $\beta$-stimulated Alk5 $5^{-1-}$ MEFs. RNA was reverse transcribed (SuperScript II; Invitrogen, Stockholm, Sweden), according to manufacturer's protocol, in the presence of random hexamers, and genespecific primers (Applied Biosystems) were used to analyze the expression of nine differentially expressed genes from the microarrays [inhibitor of DNA binding (Id)-1, Id2, Id3, growth arrest and DNA damage-inducible-45y (Gadd45g), eukaryotic translation initiation factor-5A $($ Eif5 $\alpha)$, myelocytomatosis oncogene $(c-m y c)$, growth arrest specific (Gas5), activated leukocyte cell adhesion molecule (Alcam), and decorin $(D c n)]$ together with the housekeeping gene hypoxanthine guanine phosphoribosyl transferase (Hprt). Each assay was performed in triplicate, the results were normalized to Hprt levels, and relative gene expressions between $A l k 5^{-1-}$ or TGF- $\beta 1$-stimulated Alk5 $5^{+/+}$ and unstimulated $A l k 5^{+/+}$cells were examined. Additionally, qRTPCR analysis was performed on all MEF lines, using primers for Alk1-6 (Applied Biosystems), and on murine embryonic endothelial cells, using primers for Alk1. Experiments were performed in triplicate and normalized to Hprt levels.

\section{RESULTS}

Alk5 is essential for TGF- $\beta$ signaling in MEFs. To investigate whether Alk5 is crucial for TGF- $\beta$ signal transduction, we measured expression of other members of the TGF- $\beta$ receptor family, the most likely candidates to be alternative receptors for TGF- $\beta$ signaling. Screening for these, using qRT-PCR analysis, revealed that endogenous Alkl and Alk6 expression was absent in MEFs (Fig. 1A). The other Alks were highly expressed compared with housekeeping gene expression, with Alk2 and -3 having much higher expression than Alk4 and -5 in these cells. Alk5 $5^{-1-}$ MEFs did not exhibit any increase in expression of mRNA for Alk receptors, indicating that compensatory upregulation of other TGF- $\beta$ family receptors (e.g., the BMP family) does not occur as a consequence of Alk5 deficiency. Because qRT-PCR showed the presence of Alk5 mRNA in Alk5 $5^{-1-}$ MEFs, we performed Western blot analysis and transcriptional activity assays to exclude a functional Alk5 protein. Western analysis clearly illustrated that Smad2 was phosphorylated in the Alk5 ${ }^{+/+}$MEFs upon TGF- $\beta$ stimulation, whereas phosphorylation was absent in $A l k 5^{-1-}$ cells (Fig. 1B). Thus, although Alk5 mRNA is stable in the Alk5 $5^{-/-}$MEFs, the deletion of exon 3 makes it unable to produce a functional protein. Additionally, this analysis shows that Smad2 phosphorylation by TGF- $\beta$ is conducted exclusively through Alk5 in MEFs.

Furthermore, we investigated the transcriptional activity of Smads using a reporter gene approach where Smad-binding elements (SBEs) were coupled to the luciferase gene and transfected into the different MEF cell lines. Figure $1 C$ shows that TGF- $\beta$ induced luciferase activity in WT MEFs trans- 
fected with the Smad3/Smad4-binding elements (CAGA) and the Smad4-binding SBE elements coupled to the luciferase reporter gene. Only background activity was detected when the cells, transfected with the Smad1/Smad4-inducible BMP-responsive element (BRE) reporter, were stimulated with TGF- $\beta$. No changes in luciferase activities were observed when stimulating $A l k 5^{-1-}$ cells with TGF- $\beta$. The transcriptional assay demonstrates a complete absence of TGF- $\beta$-induced Smad signaling as a result of Alk5 deficiency and that all TGF- $\beta$ Smad signals are transduced through the Smad2/3/4 branch in MEFs. Thus signaling from alternative receptor complexes in the TGF- $\beta$ family, like the ones seen in endothelial and epithelial cells, cannot be detected in this context.

It has been shown previously that TGF- $\beta$ has an inhibitory effect on cell proliferation through blockage in the late phase of G1 (8). To examine whether TGF- $\beta$-induced proliferation inhibition was altered in our MEF cell lines, we performed a cell expansion experiment. Each cell line was cultured in cell culture medium and serum with or without the addition of TGF- $\beta$. The $A l k 5^{-1-}$ cells proliferated equally well, irrespective of the presence of TGF- $\beta$, whereas the cells from the Alk $5^{+/+}$animals showed an $\sim 2.5$-fold decrease in expansion after $72 \mathrm{~h}$ of stimulation (Fig. 1D). These results demonstrate the potent inhibitory effect of TGF- $\beta$ on cell proliferation and how this effect is dependent on Alk5.

A
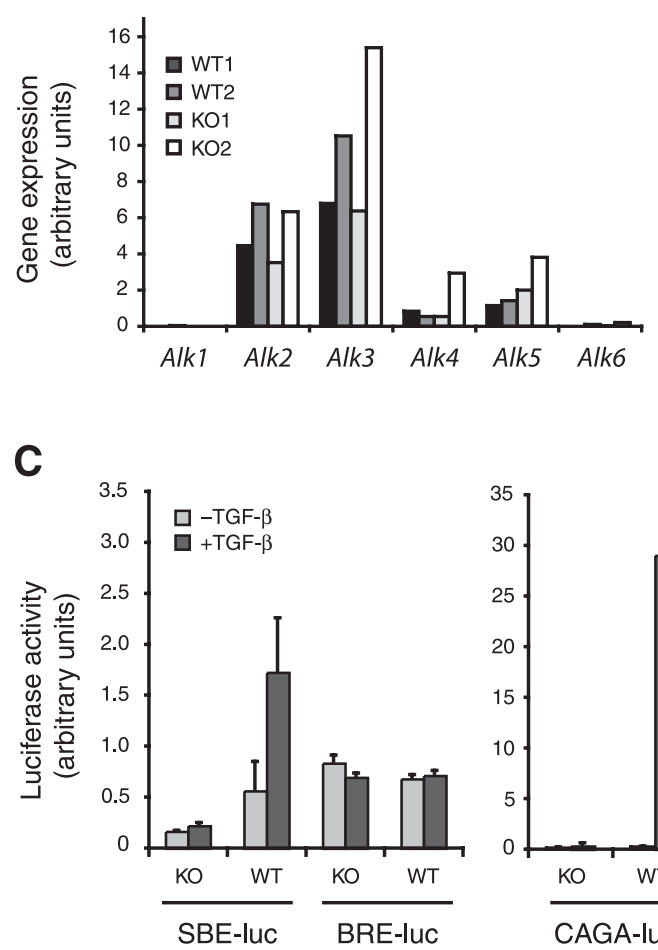

Furthermore, we studied how the absence of Alk5 affected the transcriptional response of the fibroblasts. We examined the expression of the inhibitor of the DNA binding/differentiation family of genes, known to be transcriptionally repressed by TGF- $\beta$ signaling $(11,20)$. qRT-PCR reveals that these genes were not affected by TGF- $\beta$ in Alk5 $5^{-1-}$ MEFs, whereas in $A l k 5^{+/+}$cells Id expression was strongly downregulated after TGF- $\beta$ stimulation (Fig. $2 A$ ).

To exclude receptors outside the TGF- $\beta$ superfamily and signaling pathways activated through T $\beta$ RIIs alone, we performed global gene expression profiling. We speculated that microarray analysis on Alk5 $5^{-1-}$ cells stimulated with TGF- $\beta$ would unravel possible alternative pathways for TGF- $\beta$ signaling. However, very few $(<0.05 \%)$ of the $>37,000$ spots on the microarrays had a more than twofold differential expression in the two Alk5 ${ }^{-\prime-}$ cell lines used in the experiment, none of which overlapped (Fig. 2B). The number of differentially expressed clones in these experiments was similar to when hybridizing two separate RNA extractions from the same cell line (WT1 vs. WT1), where any differential expression is due to noise. In contrast, stimulation with epidermal growth factor (EGF) generated transcriptional repression of Idl and induction of $c-m y c$ in the $A l k 5^{-/-}$cells and the $A l k 5^{+/+}$cells alike (qRT-PCR, data not shown). This serves as a positive

B
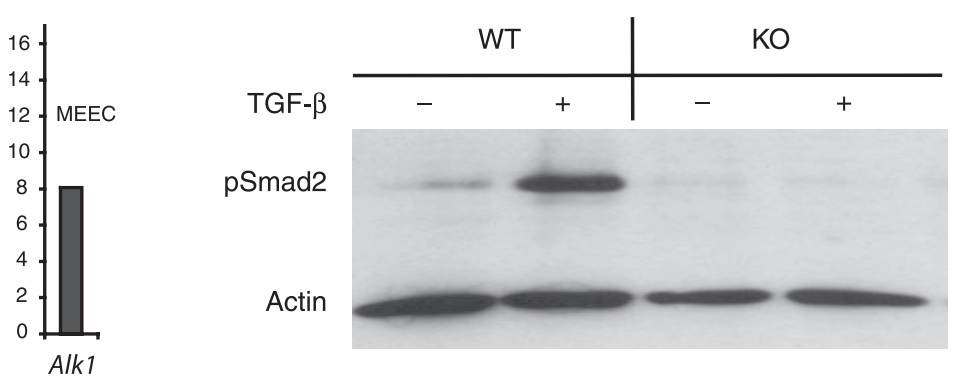

D

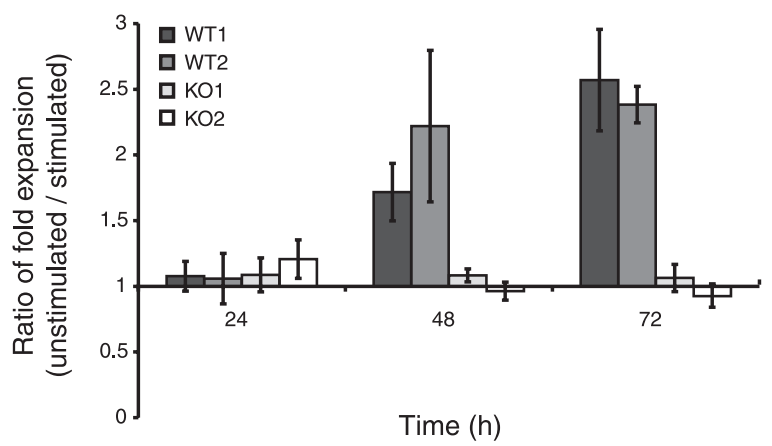

Fig. 1. Alk5 is essential for transforming growth factor (TGF)- $\beta$ induced Smad signaling. A: quantitative (q)RT-PCR screening for Alk expression in murine embryonic fibroblasts (MEFs) reveals the absence of $A l k 1$ and $A l k 6$ expression. Alk5 deficiency does not alter the expression profile of TGF- $\beta$ family receptors. Murine embryonic endothelial cells (MEECs) were used as a positive control for Alkl expression. Scale is logarithmic, where one unit represents a doubling in expression. B: Smad2 is phosphorylated in Alk $5^{+/+}$MEFs upon stimulation, whereas Smad2 phosphorylation is abrogated in Alk5 $5^{-1-}$ cells. $C$ : TGF- $\beta$ induces luciferase activity in Alk5 $5^{+/+}$cells transfected with the reporter gene coupled to the Smad3/4-binding elements (CAGA) and Smad4-binding elements (SBE). This response is not detected in the Alk5-deficient cells. Low luciferase activity is detected in cells transfected with the Smad1/4-inducible BRE coupled to the reporter gene, and this activity is not changed when cells are stimulated with TGF- $\beta$. D: unstimulated Alk $5^{+/+}$MEFs proliferate more rapidly compared with cells stimulated with TGF- $\beta$, reaching an unstimulated-to-stimulated ratio of expansion of $2-2.5$-fold in $72 \mathrm{~h}$. Proliferation of Alk5 $5^{-1-}$ MEFs is not affected by TGF- $\beta$ stimulation. Error bars represent SE of the mean. pSmad2, phosphorylated Smad2; WT, wild type; KO, knockout. 
A

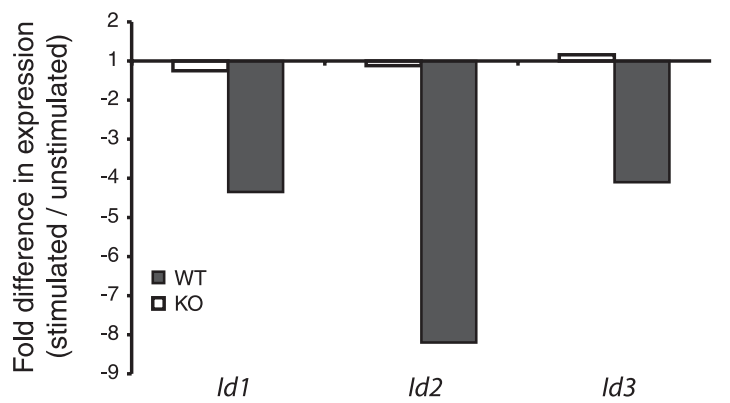

B

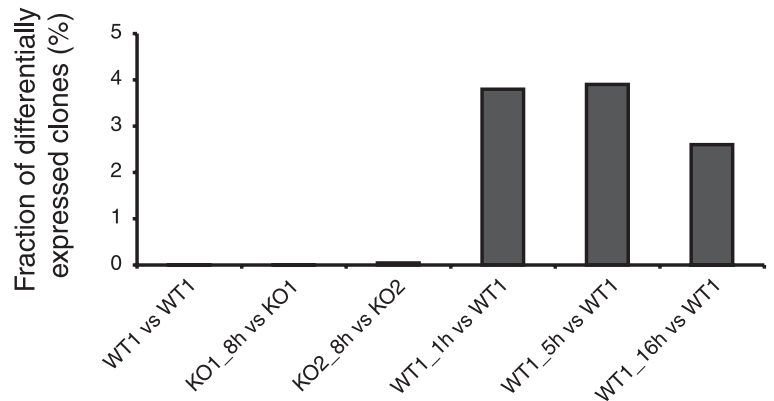

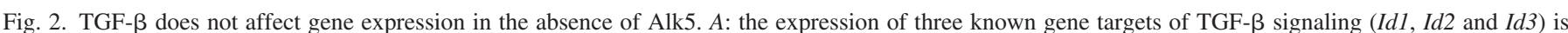

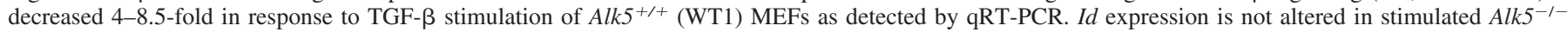

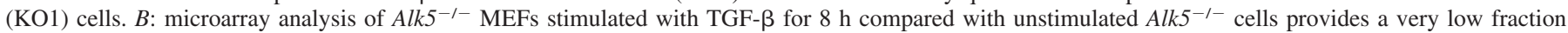

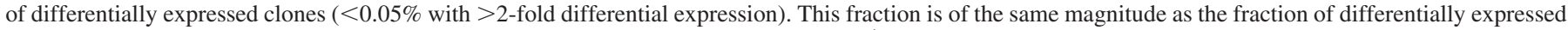

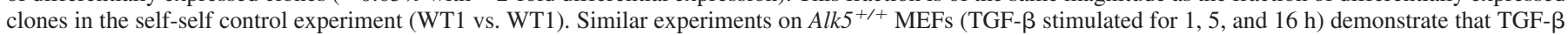
stimulation alters the expression of up to $4 \%$ of the genes in the genome.

control showing that a gene that is a target of TGF- $\beta$ signaling can be activated in the $A l k 5^{-/-}$cells by another ligand.

Microarray experiments performed on TGF- $\beta$-stimulated $A l k 5^{+/+}$cell lines resulted in differential expression of between 2.6 and $3.9 \%$ of the clones printed, demonstrating the vast effect of TGF- $\beta$ on transcriptional regulation in the genome.

Global gene expression analysis reveals 465 targets of Alk5 signaling. The substantial effects of TGF- $\beta$ made us conduct more extensive global gene expression studies to get a database of gene targets of Alk5 signaling. Total RNA was extracted from unstimulated $A l k 5^{-1-}$ and Alk5 ${ }^{+/+}$MEFs stimulated with TGF- $\beta$ for three different time periods $(1,5$, and $16 \mathrm{~h})$. cDNA from each sample was hybridized on the microarray slides together with cDNA from an unstimulated $A l k 5^{+/+}$common reference sample. We speculated that this design would result in four different data sets: early, intermediate, and late differentially expressed clones plus all the clones differentially expressed in the Alk5-deficient fibroblasts. A dye swap control experiment using one of the $A l k 5^{-1-}$ lines (KO1) showed that a replicate of one experiment using the same RNA but different dyes for the sample and reference produced highly similar results $\left(R^{2}=0.96\right.$ and 0.97 for the KO1 and the reference, respectively; data not shown), thus demonstrating the reliability of our protocols. For the 10 arrays used in this investigation, 15,202 clones passed the quality filtering. Next, we performed hierarchical cluster analysis on all the clones $(2,223)$ that had a standard deviation in expression values over the data set $>0.5$. This unsupervised analysis divided the microarray experiments in two clusters: one that included all the Alk5 $5^{-1-}$ hybridizations and another containing all the stimulated Alk $5^{+/+}$experiments (Fig. 3A). This was good evidence that the differences in gene expression among the samples were primarily due to the presence or absence of Alk5 and not because of other biological or technical variances. Because the 1-h TGF- $\beta$-stimulated Alk5 ${ }^{+/+}$cell lines seemed to be highly related, whereas the similarities in gene expression patterns in the 5- and 16-h stimulations were more dependent on the cell line, we considered our data to contain differentially expressed clones representing early responsive genes $\left(A l k 5^{+/+}\right.$MEFs stimulated for $1 \mathrm{~h}$ ), late responsive genes $\left(A l k 5^{+/+} \mathrm{MEFs}\right.$ stimulated for 5 and $16 \mathrm{~h}$ ), and genes differentially expressed in fibroblasts deficient in TGF- $\beta$ signaling. Within this set of 2,223 clones with variation among the samples, we isolated the ones that were differentially expressed due to TGF- $\beta$ stimulation or Alk5 signaling deficiency and hence likely to be the targets of Alk5 signaling. By dividing the samples into the two groups (ALK5 $5^{-1-}$ and TGF- $\beta$-stimulated $A l k 5^{+/+}$samples) defined by the unsupervised hierarchical clustering, and performing a ranked-based Wilcoxon test on the varying clones, we were able to identify 465 clones (of which 445 could be mapped to a UniGene cluster, representing 369 unique genes) that were significantly $(P \leq 0.01)$ differentially expressed as a response to TGF- $\beta$ stimulation or Alk5 signaling deficiency (Supplemental Fig. S1; available at the Physiological Genomics web site). ${ }^{1}$ We expected 22 clones by chance to be differentially expressed using this $P$ value for the 2,223 clones. Hierarchical clustering of these clones divided them in two groups, either upregulated as a response to TGF- $\beta$ stimulation and downregulated due to Alk5 deficiency, or the opposite (Fig. 3B). To get an overview of the 465 clones, they were categorized according to the biological or molecular function assigned to them in the GO database (Fig. 3C). An interesting observation was the finding of a large number of clones in the "protein folding/chaperone activity" category.

With the GoMiner software, one can investigate whether certain GO terms are enriched among the differentially expressed clones compared with their abundance on the microarray. GoMiner confirmed "protein folding" and "chaperone activity" as two of the most enriched categories, with 5.5 and 5.0 times more clones represented among the upregulated clones than one would expect if picking clones randomly from the microarray (Table 1).

Furthermore, we compared the 465 clones identified as downstream targets of TGF- $\beta$ signaling in our study, with 360 clones identified as targets of TGF- $\beta$ signaling in a similar study performed on Smad2-, Smad3-, and ERK-deficient MEFs by Yang et al. (23). Among the 360 targets presented in the previous study, 212 were found among our 15,202 clones

\footnotetext{
${ }^{1}$ The Supplemental Material for this article (Supplemental Fig. S1) is available online at http://physiolgenomics.physiology.org/cgi/content/full/
} 00303.2004/DC1. 
A

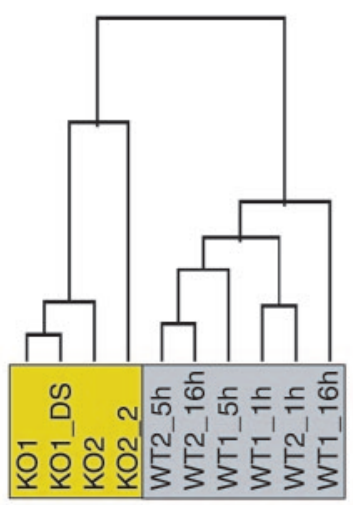

Fig. 3. Global gene expression profiling reveals 465 gene targets for TGF- $\beta$ signaling. $A$ : unsupervised hierarchical clustering of all clones with a standard deviation $>0.5$ in expression levels divides the data set in two clusters, one containing all the experiments made on Alk $5^{-1-}$ MEFs and another containing the ones made on $A l k 5^{+/+}$cells stimulated with TGF- $\beta(1,5$, and $16 \mathrm{~h})$, as shown by the resulting dendrogram. $B$ : hierarchical clustering of the 465 targets of TGF- $\beta$ signaling. $C: 179$ of the 465 clones could be assigned to categories according to classification in the Gene Ontology database; 74 were expressed sequence tags, and 212 were either unknown or belonged to a category not presented in the diagram. DS, dye swap; red, upregulated; green, downregulated; $\mathrm{KO} 2$ 2, repeated RNA extraction from $\mathrm{KO} 2$ cell line.

\section{C \\ Differentially expressed genes (KO vs stimulated WT)

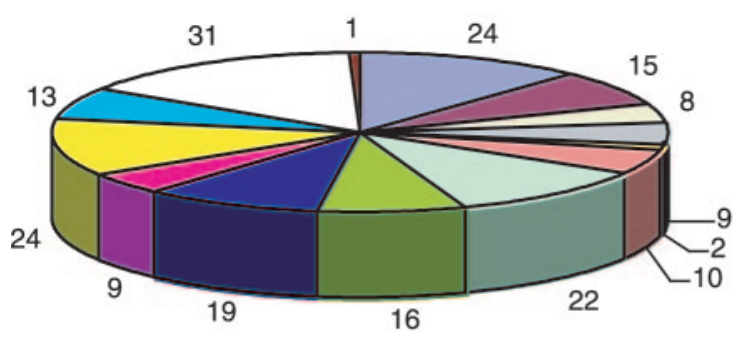 \\ 口Transcription regulation aCell cycle 口Cell surface receptors 口Apoptosis 口Signaling ligands 口Protein synthesis 口ECM/adhesion \\ ㅁPProtein folding/Chaperone activity aCytoskeleton \\ 口RNA binding/processing \\ 口Metabolism \\ 口Intracellular signaling \\ पTransport \\ 口DNA repair}

\section{Other/unknown function: 212 ESTs: 74}

B

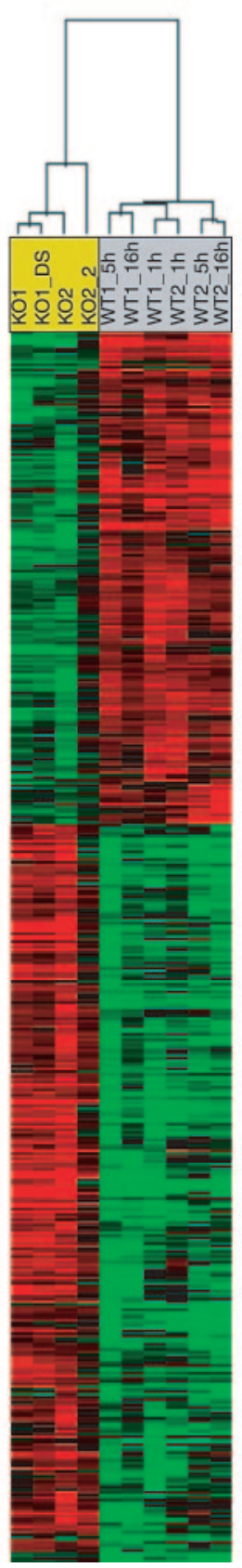

that passed quality filtering. Twenty-nine of these 212 were also present in our list of 465 targets. These 29 clones correspond to 27 unique genes (Table 2).

To validate the results obtained from the microarray experiments, we performed qRT-PCR, measuring gene expression of nine genes with varying magnitude of differential expression. Relative mRNA levels between $A l k 5^{-1-}$ cells as well as Alk $5^{+/+}$cells stimulated with $\mathrm{TGF}-\beta$ and unstimulated Alk5 $5^{+/+}$cells were compared (Table 3 ). The resulting data revealed that in $77 \%$ (27 of 35 ) of the assays performed, an upregulated gene in the microarray experiment was also upregulated when using the qRT-PCR method and vice versa. The validation of the microarray was even stronger when only looking at genes in samples with a differential expression of more than or equal to twofold, where $100 \%(18 / 18)$ of the assays showed the same direction of differential expression in both methods used.

\section{DISCUSSION}

The findings of Alk1 as an alternative receptor for TGF- $\beta$ in endothelial cells (16) raise the question of alternative receptors in other cell types. We reasoned that a model with a complete absence of the classical Alk5 receptor would be ideal to elucidate this question. We have conducted extensive studies, including TGF- $\beta$ family receptor screening, Smad signaling analysis, and transcriptional and functional assays as well as global gene expression profiling on Alk5-deficient MEFs without finding any signs of alternative receptors for TGF- $\beta$ signaling in these cells. 
Table 1. GO categories enriched by genes regulated by TGF- $\beta$ signaling

\begin{tabular}{|c|c|c|c|}
\hline GO Category & Total & Up & $P$ Value \\
\hline Physiological process & 3,373 & 74 & 0.0420 \\
\hline Metabolism & 2,379 & 58 & 0.0113 \\
\hline Biosynthesis & 477 & 15 & 0.0424 \\
\hline Protein biosynthesis & 273 & 11 & 0.0167 \\
\hline Translation & 92 & 6 & 0.0088 \\
\hline Protein metabolism & 995 & 33 & 0.0008 \\
\hline Protein folding & 65 & 7 & 0.0002 \\
\hline Cell motility & 78 & 6 & 0.0039 \\
\hline Nucleocytoplasmic transport & 55 & 5 & 0.0041 \\
\hline Nuclear organization and biogenesis & 86 & 5 & 0.0258 \\
\hline Translation regulator activity & 71 & 9 & 0.0000 \\
\hline $\begin{array}{l}\text { Translation factor activity, nucleic acid } \\
\text { binding }\end{array}$ & 68 & 9 & 0.0000 \\
\hline Translation initiation factor activity & 46 & 8 & 0.0000 \\
\hline Binding & 2,651 & 66 & 0.0020 \\
\hline Nucleotide binding & 660 & 22 & 0.0073 \\
\hline Purine nucleotide binding & 651 & 22 & 0.0062 \\
\hline Adenyl nucleotide binding & 529 & 18 & 0.0128 \\
\hline ATP binding & 524 & 18 & 0.0116 \\
\hline Chaperone activity & 93 & 9 & 0.0001 \\
\hline Nuclear membrane & 51 & 5 & 0.0030 \\
\hline Cell junction & 55 & 5 & 0.0041 \\
\hline Enzyme inhibitor activity & 56 & 5 & 0.0045 \\
\hline Nucleolus & 56 & 5 & 0.0045 \\
\hline GO Category & Total & Down & $P$ Value \\
\hline Vacuole & 61 & 7 & 0.0032 \\
\hline Lytic vacuole & 54 & 7 & 0.0016 \\
\hline Lysosome & 54 & 7 & 0.0016 \\
\hline Extracellular & 669 & 35 & 0.0021 \\
\hline Extracellular space & 604 & 32 & 0.0028 \\
\hline Extracellular matrix & 113 & 9 & 0.0103 \\
\hline Protein binding & 989 & 46 & 0.0043 \\
\hline Peptidase activity & 190 & 11 & 0.0425 \\
\hline
\end{tabular}

For Gene Ontology (GO) categories, subcategories are indented below parent categories. Total, total no. of filtered genes matched to category; Up, no. of genes upregulated in transforming growth factor (TGF)- $\beta$-stimulated wild types (WTs) matched to category; Down, no. of genes downregulated in TGF- $\beta$-stimulated WTs matched to category; $P$ value, significance of enrichment of up/downregulated genes as calculated by GOMiner.

Global gene expression profiling only detects transcriptional changes, and therefore posttranslational events could be overseen. For example, recently it has been shown that the TGF- $\beta$ superfamily type II receptor BMPR-II alone can interact with LIM kinase-1 (LIMK1), and that LIMK1 is released on BMP4 binding to BMPR-II (3). Unbound LIMK1 will then regulate actin dynamics through phosphorylation of cofilin. These kinds of posttranslational events might not be detected by gene expression analysis, although this is unlikely, since such changes in the cell are likely to affect global gene expression profiles to some degree. Thus, taken together, our data strongly suggest that TGF- $\beta$ signals exclusively through receptor complexes containing Alk5 in fibroblasts.

One microarray study on murine fibroblasts has previously been published (23) where the authors investigated the transcriptome of MEFs lacking Smad2, Smad3, or ERK signaling while having other TGF- $\beta$ signaling pathways intact. Here we have the advantage of $A l k 5^{-/-}$cells that completely lack responses to TGF- $\beta$ signaling and thus should reveal the majority of its gene targets. While in our study we identified 465 clones as targets of TGF- $\beta$ signaling, Yang et al. presented
Table 2. Gene targets of TGF- $\beta$ signaling in common with Yang et al. (23)

\begin{tabular}{ll}
\hline \hline \multicolumn{1}{c}{ Gene Name } & Gene Symbol \\
\hline RIKEN cDNA 2610312E17 gene & 2610312E17 \\
Branched chain aminotransferase 1, cytosolic & Bcat1 \\
Basic helix-loop-helix domain containing, class B2 & Bhlhb2 \\
Bc12-associated athanogene 2 & Bag2 \\
Filamin, beta & Flnb \\
Connective tissue growth factor & Ctgf \\
RIKEN cDNA B230104P22 gene & B230104P22 \\
Myelocytomatosis oncogene & Myc \\
RIKEN cDNA 1110017C15 gene & 1110017 C15 \\
Peroxisome proliferative activated receptor, gamma, & \\
coactivator-related 1 & Pprc1 \\
Nucleolar and coiled-body phosphoprotein 1 & Nolc1 \\
RIKEN cDNA 2210403K04 gene & $2210403 K 04$ \\
Synaptic nuclear envelope 2 & Syne2 \\
Zinc finger protein 395 & Zfp395 \\
High mobility group box transcription factor 1 & Hbp1 \\
Sestrin 1 & Sesn1 \\
Platelet derived growth factor receptor, alpha polypeptide & Pdgfra \\
F11 receptor & F11r \\
Melanoma antigen, family D, 1 & Maged1 \\
Zinc finger protein 36, C3H type-like 1 & Zfp3611 \\
Laminin, alpha 5 & Lama5 \\
RIKEN cDNA 1700065A05 gene & 1700065 A05 \\
Protein tyrosine phosphatase, receptor type, F & Ptprf \\
Cyclin-dependent kinase inhibitor 2C (p18, inhibits CDK4) & Cdkn2c \\
RIKEN cDNA 1110065D03 gene & 1110065D03 \\
RIKEN cDNA 5830403L16 gene & Glu1 \\
Shroom & Shrm \\
\hline
\end{tabular}

360, and among these two data sets, 29 targets were overlapping. The 27 unique genes that these 29 clones represent include both known targets of TGF- $\beta$ signaling, like $c-m y c$ and Pdgfra, and some novel targets with interesting functions. In our study, Pdgfra is considerably downregulated in all the TGF- $\beta$-stimulated WT MEFs and upregulated in three of four Alk $5^{-1-}$ experiments. Pdgfra is a possible indirect key mediator of the TGF- $\beta$-induced proliferation block, since it stimulates proliferation of fibroblasts and has been shown to be

Table 3. qRT-PCR confirmation of microarray data

\begin{tabular}{|c|c|c|c|c|c|}
\hline \multirow[b]{2}{*}{ Gene } & \multirow[b]{2}{*}{ Method } & \multicolumn{4}{|c|}{ Fold Differentially Expressed } \\
\hline & & KO1 & $\mathrm{KO} 2$ & WT1_5h & WT2_5h \\
\hline \multirow[t]{2}{*}{$c-m y c$} & qRT-PCR & -3.1 & -3.4 & 1.1 & 1.4 \\
\hline & microarray & -1.9 & -2.9 & 1.8 & 1.6 \\
\hline \multirow[t]{2}{*}{ Gas 5} & qRT-PCR & 4.2 & 2.7 & 3.1 & 12.5 \\
\hline & microarray & -1.2 & -1.3 & 1.9 & 1.6 \\
\hline \multirow[t]{2}{*}{ elF5a } & qRT-PCR & -1.1 & -1.4 & 1.1 & 1.0 \\
\hline & microarray & -1.1 & -1.8 & 2.0 & 1.8 \\
\hline \multirow[t]{2}{*}{ IdI } & qRT-PCR & 2.7 & 1.5 & -4.3 & -3.0 \\
\hline & microarray & 3.0 & & -6.3 & -1.9 \\
\hline \multirow[t]{2}{*}{$I d 2$} & qRT-PCR & -1.7 & 1.8 & -8.2 & -1.4 \\
\hline & microarray & 1.4 & 3.4 & -4.9 & -3.4 \\
\hline \multirow[t]{2}{*}{ Id 3} & qRT-PCR & 1.5 & 3.5 & -4.1 & 1.5 \\
\hline & microarray & 3.2 & 2.6 & -4.6 & -1.5 \\
\hline \multirow[t]{2}{*}{ Gadd $45 g$} & qRT-PCR & 1.3 & -4.3 & 2.6 & 3.3 \\
\hline & microarray & -1.1 & 1.3 & 3.6 & 5.2 \\
\hline \multirow[t]{2}{*}{ Alcam } & qRT-PCR & 4.3 & 55.2 & -1.1 & 4.8 \\
\hline & microarray & 8.2 & 8.2 & -4.5 & -1.6 \\
\hline \multirow[t]{2}{*}{ Dcn } & qRT-PCR & 9.3 & 15.3 & -3.6 & 2.4 \\
\hline & microarray & 7.6 & 9.3 & -10.0 & -1.4 \\
\hline
\end{tabular}

$\mathrm{KO}=\mathrm{ALK} 5^{-1-} . \mathrm{WT}=\mathrm{ALK} 5^{+/+} .{ }_{-} 5 \mathrm{~h}$ indicates 5 -h stimulation with TGF- $\beta$. qRT-PCR, quantitative RT-PCR. 
downregulated by overexpression of T $\beta$ RII in NIH-3T3 fibroblasts (4).

Another gene overlapping with the study by Yang et al. (23) is Bcl-2-associated athanogene-2 (Bag2), previously unknown as a target of TGF- $\beta$ signaling. Bag2 is involved in apoptosis and chaperone regulation and was recently reported to be induced by the p38 MAPK pathway (21). In accordance with this, Bag2 is downregulated in three of four of our Alk5 $5^{-/-}$ experiments while upregulated in all the TGF- $\beta$-stimulated WTs. The finding of Bag2 is part of the interesting observation that two of the most significant differentially expressed categories, according to GoMiner analysis of our data, are the protein folding and chaperone categories. These include ATPbinding cassette, subfamily E (OABP), member 1 (Abcel), Bag2, heat shock protein A (Hspa9a), Hsp105, Hspe1, Hspdl, Hspa5bpl, chaperonin subunit 2 (Cct2), Cct3, Cct8, t-complex protein-1 (Tcpl), peptidylprolyl isomerase D (Ppid), and DNAJ homolog subfamily A, member 1 (Dnajal). Also interesting is that the vast majority of these genes were upregulated as a response to TGF- $\beta$ stimulation or downregulated in the Alk5-deficient cells. Analysis after only $1 \mathrm{~h}$ of TGF- $\beta$ stimulation revealed a significant overrepresentation of the chaperone activity and protein folding genes. This significance was lost at later time points, suggesting that TGF- $\beta$ stimulation rapidly and transiently induces the expression of chaperones. Intriguingly, a large number of the other significantly overrepresented categories of target genes, identified by GoMiner analysis, are also involved in different aspects of protein processing. Among these, the most striking finding is the upregulation of genes involved in translation. Of the 71 genes involved in "translation regulator activity" spotted on the microarray, as many as nine were significantly upregulated in response to TGF- $\beta$ stimulation. Additionally, eight of these nine genes were subunits of eukaryotic initiating factors (eIFs), responsible for the first step in protein biosynthesis. These include Eif2, subunit 3, structural gene X-linked (Eif2s3x), Eif3s9, Eif2s1, Eif2s2, Eif5a, and Eif4g1. Furthermore, these categories exhibited kinetics similar to the protein folding and chaperone genes with rapid upregulation as a response to TGF- $\beta$ signaling.

Comparing our differentially expressed genes with identified gene targets from other studies performed on human lung fibroblasts (1) and human dermal fibroblasts (22), we obtained an overlap of $\sim 10 \%$. Because of the differences in experimental design and species, extensive comparisons between our study and these two were not performed. However, $M y c$ and connective tissue growth factor (Ctgf) were identified in both our study and the one performed by Yang et al. (23) as well as in the study performed on human lung fibroblasts, indicating these genes to be somewhat species-independent targets of TGF- $\beta$ signaling. Furthermore, it is interesting to note the immense downregulation of the $I d$ genes by TGF- $\beta$ in our study. This is in contrast to findings in the study of human lung fibroblasts, where the $I D$ genes were induced by TGF- $\beta$ (1). On the contrary, a microarray study of epithelial cells reported a repression of $I D 1, I D 2$, and $I D 3$ expression as a response to TGF- $\beta$, in agreement with our results (7). This downregulation of ID genes is implicated in the mechanism of proliferation arrest exercised by TGF- $\beta$ in these cells. Thus our findings showing an Id expression in MEFs similar to the expression in adult epithelial cells indicate that the downregulation of these genes is part of the proliferation inhibition by TGF- $\beta$ in MEFs.

To conclude, the use of $A l k 5^{-1-}$ MEFs has given us the unique opportunity to investigate and exclude the use of alternative receptors for TGF- $\beta$ in fibroblasts. Additionally, the absence of alternative receptors makes this model ideal for the identification of target genes of TGF- $\beta$ signaling, which will be important for understanding the mechanisms behind the diverse effects of this multifunctional cytokine.

\section{ACKNOWLEDGMENTS}

We thank Dr. Mikael Sigvardsson, Dr. Peter ten Dijke, and Johan VallonChristersson for valuable discussions and advice.

\section{GRANTS}

This work was supported by grants to S. Karlsson from CancerfondenSweden, Barncancerfonden-Sweden, The Medical Research Council-Sweden, and The Juvenile Diabetes Research Foundation and a clinical research award from Lund University Hospital and by grants to M. Ringnér from the Swedish Research Council. This work was also supported by a grant to S. Karlsson and M. Ringnér from the Research School in Genomics and BioinformaticsSweden. The Lund Stem Cell Center is supported by a Center of Excellence Grant in Life Sciences from the Swedish Foundation for Strategic Research.

\section{REFERENCES}

1. Chambers RC, Leoni P, Kaminski N, Laurent GJ, and Heller RA. Global expression profiling of fibroblast responses to transforming growth factor- $\beta 1$ reveals the induction of inhibitor of differentiation- 1 and provides evidence of smooth muscle cell phenotypic switching. Am J Pathol 162: 533-546, 2003.

2. Chang H, Brown CW, and Matzuk MM. Genetic analysis of the mammalian transforming growth factor- $\beta$ superfamily. Endocr Rev 23: 787-823, 2002.

3. Foletta VC, Lim MA, Soosairajah J, Kelly AP, Stanley EG, Shannon M, He W, Das S, Massague J, Bernard O, and Soosairaiah J. Direct signaling by the BMP type II receptor via the cytoskeletal regulator LIMK1. J Cell Biol 162: 1089-1098, 2003.

4. Goldberg HJ, Huszar T, Mozes MM, Rosivall L, and Mucsi I. Overexpression of the type II transforming growth factor- $\beta$ receptor inhibits fibroblasts proliferation and activates extracellular signal regulated kinase and c-Jun N-terminal kinase. Cell Biol Int 26: 165-174, 2002.

5. Goumans MJ, Valdimarsdottir G, Itoh S, Lebrin F, Larsson J, Mummery C, Karlsson S, and ten Dijke P. Activin receptor-like kinase (ALK)1 is an antagonistic mediator of lateral TGFß/ALK5 signaling. Mol Cell 12: 817-828, 2003.

6. Harris MA, Clark J, Ireland A, Lomax J, Ashburner M, Foulger R, Eilbeck K, Lewis S, Marshall B, Mungall C, Richter J, Rubin GM, Blake JA, Bult C, Dolan M, Drabkin H, Eppig JT, Hill DP, Ni L, Ringwald M, Balakrishnan R, Cherry JM, Christie KR, Costanzo MC, Dwight SS, Engel S, Fisk DG, Hirschman JE, Hong EL, Nash RS, Sethuraman A, Theesfeld CL, Botstein D, Dolinski K, Feierbach B, Berardini T, Mundodi S, Rhee SY, Apweiler R, Barrell D, Camon E, Dimmer E, Lee V, Chisholm R, Gaudet P, Kibbe W, Kishore R, Schwarz EM, Sternberg P, Gwinn M, Hannick L, Wortman J, Berriman $\mathrm{M}$, Wood $\mathrm{V}$, de la Cruz $\mathrm{N}$, Tonellato $\mathrm{P}$, Jaiswal $\mathrm{P}$, Seigfried $\mathrm{T}$, and White R. The Gene Ontology (GO) database and informatics resource. Nucleic Acids Res 32 (Database issue): D258-D261, 2004.

7. Kang Y, Chen CR, and Massague J. A self-enabling TGFß response coupled to stress signaling: Smad engages stress response factor ATF3 for Id1 repression in epithelial cells. Mol Cell 11: 915-926, 2003.

8. Kletsas D, Stathakos D, Sorrentino V, and Philipson L. The growthinhibitory block of TGF- $\beta$ is located close to the G1/S border in the cell cycle. Exp Cell Res 217: 477-483, 1995.

9. Lai YT, Beason KB, Brames GP, Desgrosellier JS, Cleggett MC, Shaw MV, Brown CB, and Barnett JV. Activin receptor-like kinase 2 can mediate atrioventricular cushion transformation. Dev Biol 222: 1-11, 2000.

10. Larsson J, Goumans MJ, Sjostrand LJ, van Rooijen MA, Ward D, Leveen P, Xu X, ten Dijke P, Mummery CL, and Karlsson S. Abnor- 
mal angiogenesis but intact hematopoietic potential in TGF- $\beta$ type I receptor-deficient mice. EMBO J 20: 1663-1673, 2001.

11. Ling MT, Wang X, Tsao SW, and Wong YC. Down-regulation of Id-1 expression is associated with TGF $\beta 1$-induced growth arrest in prostate epithelial cells. Biochim Biophys Acta 1570: 145-152, 2002.

12. Liu Y and Ringner M. Multiclass discovery in array data. BMC Bioinformatics 5: 70, 2004.

13. Massague J, Blain SW, and Lo RS. TGF $\beta$ signaling in growth control, cancer, and heritable disorders. Cell 103: 295-309, 2000.

14. Meyer K, Lee JS, Dyck PA, Cao WQ, Rao MS, Thorgeirsson SS, and Reddy JK. Molecular profiling of hepatocellular carcinomas developing spontaneously in acyl-CoA oxidase-deficient mice: comparison with liver tumors induced in wild-type mice by a peroxisome proliferator and a genotoxic carcinogen. Carcinogenesis 24: 975-984, 2003.

15. Nathan C and Sporn M. Cytokines in context. J Cell Biol 113: 981-986, 1991.

16. Oh SP, Seki T, Goss KA, Imamura T, Yi Y, Donahoe PK, Li L, Miyazono K, ten Dijke P, Kim S, and Li E. Activin receptor-like kinase 1 modulates transforming growth factor- $\beta 1$ signaling in the regulation of angiogenesis. Proc Natl Acad Sci USA 97: 2626-2631, 2000.

17. Ringner M, Veerla S, Andersson S, Staaf J, and Hakkinen J. ACID: a database for microarray clone information. Bioinformatics 20: 2305-2306, 2004.
18. Roberts AB. Molecular and cell biology of TGF- $\beta$. Miner Electrolyte Metab 24: 111-119, 1998.

19. Saal LH, Troein C, Vallon-Christersson J, Gruvberger S, Borg A, and Peterson C. BioArray Software Environment (BASE): a platform for comprehensive management and analysis of microarray data. Genome Biol 3: SOFTWARE0003, 2002.

20. Siegel PM, Shu W, and Massague J. Mad upregulation and Id2 repression accompany transforming growth factor (TGF)- $\beta$-mediated epithelial cell growth suppression. J Biol Chem 278: 35444-35450, 2003.

21. Ueda K, Kosako H, Fukui Y, and Hattori S. Proteomic identification of Bcl2-associated athanogene 2 as a novel MAPK-activated protein kinase 2 substrate. J Biol Chem 279: 41815-41821, 2004.

22. Verrecchia F, Chu ML, and Mauviel A. Identification of novel TGF- $\beta$ /Smad gene targets in dermal fibroblasts using a combined cDNA microarray/promoter transactivation approach. J Biol Chem 276: 1705817062, 2001

23. Yang YC, Piek E, Zavadil J, Liang D, Xie D, Heyer J, Pavlidis P, Kucherlapati R, Roberts AB, and Bottinger EP. Hierarchical model of gene regulation by transforming growth factor- $\beta$. Proc Natl Acad Sci USA 100: 10269-10274, 2003.

24. Zeeberg BR, Feng W, Wang G, Wang MD, Fojo AT, Sunshine M, Narasimhan S, Kane DW, Reinhold WC, Lababidi S, Bussey KJ, Riss J, Barrett JC, and Weinstein JN. GoMiner: a resource for biological interpretation of genomic and proteomic data. Genome Biol 4: R28, 2003.

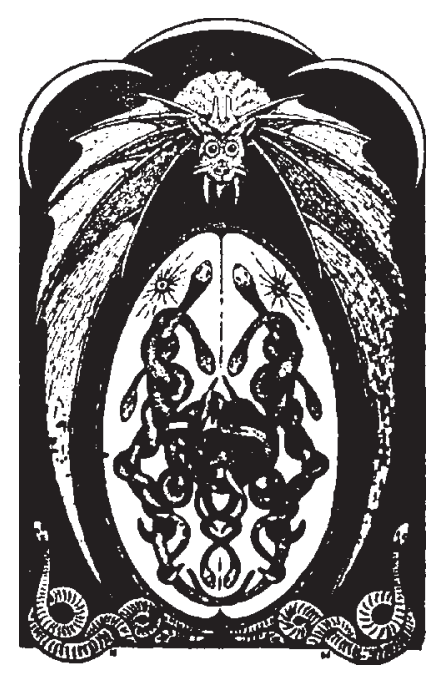

